Check for updates

Cite this: RSC Adv., 2018, 8, 11330

Received 7th December 2017

Accepted 7th March 2018

DOI: $10.1039 / c 7 r a 13116 j$

rsc.li/rsc-advances

\section{Enhanced photoconductivity in CdS/betanin composite nanostructures $\uparrow$}

\begin{abstract}
N. Susha, ${ }^{a}$ K. Nandakumar ${ }^{\text {(D) }}{ }^{\mathrm{b}}$ and Swapna S. Nair (D) *a
Development of novel materials for thin film solar cells are gaining significant attention due to their tunable wide bandgap and extensive application potential in flexible energy harvesters. CdS is a known window material for thin film solar cells. Tuning of the photoconductivity of CdS by doping, substitution and grain size tailoring is widely attempted by researchers. Inorganic core/shell structures like CdS/CdSe, $\mathrm{CdS} / \mathrm{ZnS}$ etc. are other possible candidates with band gap tailorability. However, such attempts are rare in tailoring the photoconductivity by providing an organic shell over the inorganic core. Here the authors synthesised CdS/betanin core/shell structures using wet chemical routes. Spectroscopic studies show that the composite structure is core/shell like, with CdS as the core and betanin (a natural dye), as the outer shell with an average core particle size of $10 \mathrm{~nm}$. The absorption spectra of the composite system show the signature of an additional band in the lower wavelength region and it is redshifted with increase in betanin percentage. The intermediate band observed in the energy of $\sim 1.75 \mathrm{eV}$, helps CdS to enhance the rate of absorption. Simultaneous absorbance of lower and higher energy photons from the solar radiation can increase the efficiency of CdS based solar cells. A huge enhancement in conductivity is observed in $\mathrm{CdS} /$ betanin composites on illumination with white light due to the transfer of photogenerated electrons from the conduction band of betanin dye to the conduction band of CdS.
\end{abstract}

\section{Introduction}

Semiconductors, especially silicon (Si) based electronic devices, inexorably paved the way for the modern technology of computation and electronics. The innovation and tailoring of "nano" introduced wide varieties of material choices for the device fabrication other than silicon, which has had a dominance in the semiconductor industry for the last 50 years. Exploring an efficient low-cost alternative for $\mathrm{Si}$, to meet its marketing demands, is still a challenge for the researchers working in the field of electronic device fabrication. Alterations in electronic gadgets such as scaling down, have extended the life span, while higher efficiency empowered their advancement in an unlimited number of applications and hence researchers are so energized in embracing wide band gap materials in electronic device fabrication. ${ }^{1,2}$ Wide bandgap semiconductors (materials which have band gap relatively greater than conventional silicon) like silicon carbide (SiC, band gap $3.3 \mathrm{eV}$ ) and gallium nitride (GaN, band gap $3.4 \mathrm{eV}$ ) thus emerged as the front running solutions for the power and heat issues of silicon (band gap $1.1 \mathrm{eV}$ ). Comparing to $\mathrm{Si}, \mathrm{SiC}$ is the most maturely

${ }^{a}$ Dept. of Physics, Central University of Kerala, Kasaragod, India - 671314

${ }^{b}$ International and Inter University Centre for Nanoscience and Nanotechnology, Mahatma Gandhi University, Kottayam, India - 686 560. E-mail: swapna@ cukerala.ac.in

$\dagger$ Electronic supplementary information (ESI) available. See DOI: 10.1039/c7ra13116j developed wide band gap material which has high-temperature/ voltage stability with $20 \%$ higher efficiency. ${ }^{3,4}$ But presently its production is much more expensive than silicon. GaN is one among the widely explored cost effective alternative that offers similar performance of SiC. However, the problems associated with the synthesis of GaN demands alternative material search in this regard.

It is reported ${ }^{5}$ that tailoring the size, structure, morphology and chemical composition of nanomaterials can deliberately tune their properties and its integration leads to nanoscale device fabrication. So, the migration to novel materials other than conventional $\mathrm{SiC}$ and $\mathrm{GaN}$ can pave way to enhanced efficiency of electronic devices.

Quantum dots, the ultrafine nanoparticles (size below 10 $\mathrm{nm}$ ), offer higher band gap than their bulk cousins due to the size dependent quantum confinement effects. This property of quantum dot helps them to harvest the hot electrons from the material with high energy photons and generating multiple charge carriers which offers new ways to attain greater efficiency in the next generation solar cells. ${ }^{6}$ For the last few years, II-VI group semiconductors attracted researchers owing to its wide band gap, availability, easy synthesis and band gap tunability. ${ }^{7-9}$ Among them, CdS is one of the most prominent candidate which has potential application in the field of optoelectronics. Tailoring of band gap of CdS is possible by varying the experimental conditions such as concentration, $\mathrm{pH}$, stoichiometry, temperature etc. Experimentalists used organic as well as 
(a)
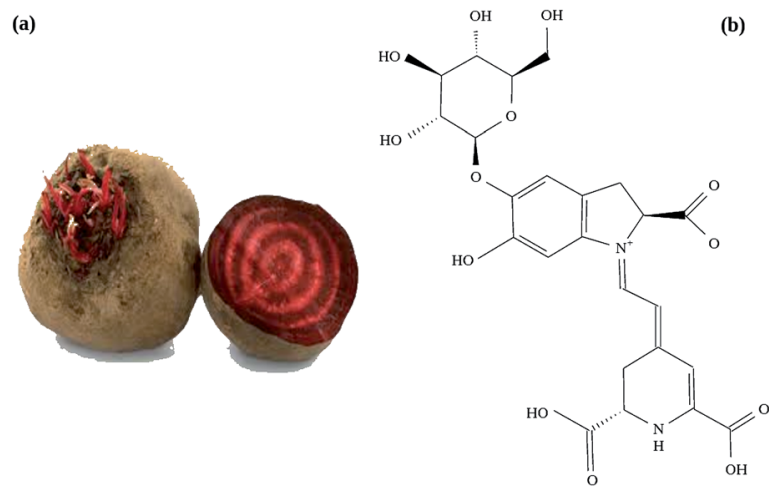

Fig. 1 (a) Edible vegetable beet root and its inner portion, from which the betanin dye solution is extracted out using boiling method and (b) the structure of betanin with two nitrogen bonds $-\mathrm{NH}-$ and $=\mathrm{N}-$ with molecular formula $\mathrm{C}_{24} \mathrm{H}_{27} \mathrm{~N}_{2} \mathrm{O}_{13}$.

inorganic surfactants ${ }^{\mathbf{1 0 - 1 3}}$ in conjunction with the precursors to stabilize the particle growth and to avoid agglomeration in CdS nanoparticles. Accordingly, a large fraction of the particles is observed to be distributed in the size range of 2-10 $\mathrm{nm}$ (ref. 10) and are categorized as semiconductor quantum dots (SQDs).

In solar cells, semiconductor has to fulfil both the task of light absorber and charge carrier transporter. But in Dye Sensitized Solar Cells (DSSC), light absorption is the responsibility of "sensitizer", and the semiconductor in which the sensitizer is attached transports the charge. ${ }^{14}$ Researchers tried both organic and natural dyes as sensitizer and studied how effectively it absorbs the light. $\mathrm{TiO}_{2}$ is a well-known charge transporter which has wide band gap, later researchers replaced it by other wide band gap oxides such as $\mathrm{ZnO},{ }^{15} \mathrm{Nb}_{2} \mathrm{O}_{5}, \mathrm{SnO}_{2}$, $\mathrm{In}_{2} \mathrm{O}_{3}, \mathrm{WO}_{3}, \mathrm{Ta}_{2} \mathrm{O}_{5}, \mathrm{ZrO}_{2}{ }^{16}$ etc. Researchers also examined the performance of II-VI group elements such as CdSe, CdTe, and CdS semiconductors as a central part of DSSC. ${ }^{17}$

Wide varieties of synthetic as well as natural dyes are already being a part of DSSC research. In addition to DSSC, dyes are used in core/shell nanostructure as both core and shell depending on the application of interest. Dye based organic/ inorganic core/shell structure has tremendous application in the field of material science, microelectronics and biotechnology. Here, in the present investigation, we have used a natural dye (betanin, $\mathrm{C}_{24} \mathrm{H}_{27} \mathrm{~N}_{2} \mathrm{O}_{13}$ ) extracted from the red beetroot (Beta vulgaris) (Fig. 1) - a well-known antioxidant ${ }^{\mathbf{1 8 , 1 9}}$ as a medium for the growth of CdS nanoparticles. CdS and the CdS/betanin composite nanostructures are then structurally characterized for crystallinity and phase purity and optically characterized for absorption and photoconductivity.

\section{Experimental}

\section{Synthesis}

Chemical co-precipitation method is opted for the synthesis of CdS nanoparticles with $\mathrm{CdSO}_{4}, \mathrm{CS}\left(\mathrm{NH}_{2}\right)_{2}$ and $\mathrm{NH}_{4} \mathrm{OH}$ solutions as cadmium source, sulfur source and complexing agent respectively. To the $\mathrm{CdSO}_{4}$ solution, $\mathrm{NH}_{4} \mathrm{OH}$ is added dropwise until the $\mathrm{pH}$ value reaches 10 . After 15 minutes, the precipitate is filtered and dried in air. The betanin solution is prepared from the fresh beet root using deionized water as a solvent. No acidification $^{20}$ is tried here. Dark pink coloured solution obtained is kept in a conical flask. The procedure of CdS synthesis is repeated with different betanin amount $(6 \%, 10 \%, 20 \%$ and $50 \%$ ). The obtained precipitate is filtered, dried and grinded well. The colour of the sample varies from light yellow (without betanin) to dark brown as the dye content increases (Fig. 9).

\section{Characterisation}

Structural characterisation of the samples is done using X-ray diffraction (XRD Rigaku Miniflex 600 with $\mathrm{CuK}_{\alpha}=1.5406 \AA$ ) and the patterns are recorded in the $\theta-2 \theta$ mode for the range $20-60^{\circ}$. Thermal analysis of the samples is done using thermogravimetric analysis (TGA, PerkinElmer-STA 6000). Shape and size of the particles, which are the property deciding factors of nanoparticles, are recorded by high resolution Transmission Electron Microscopy (TEM, JEOL, JEM-2100). The surface chemistry of the sample is done by X-ray Photoelectron Spectroscopy (XPS, PHI 5000 Versa Probe II, ULVAC PHI-USA) with Al-K $\alpha$ source (power $33 \mathrm{~W}$ ). PerkinElmer (Lambda 35) UV-Vis spectrophotometer is used to record its wavelength (380-800 $\mathrm{nm}$ ) depended absorption spectrum. Precision impedance analyser (Wayne Kerr, $6500 \mathrm{~B}$ ) is used to study the dielectric properties as well as the photoconductivity (using 300 watt incandescent bulb) of the samples.

\section{Results and discussion}

\section{$\mathrm{X}$-ray diffraction}

Diffraction patterns of pure CdS as well as CdS/betanin composite are shown in Fig. 2. Generally, CdS exists in two crystal forms - hexagonal and cubic, of which the hexagonal form is more stable $\mathrm{e}^{21}$ at room temperature. From the figure, it is clear that the CdS exhibits mixed crystal structure with less intense hexagonal peak. As the betanin percentage increases, the peak corresponding to the plane $[200 \mathrm{c}]$ diminishes and become broad due to the smaller particle formation. This is because of the shelling of betanin dye. The grain growth

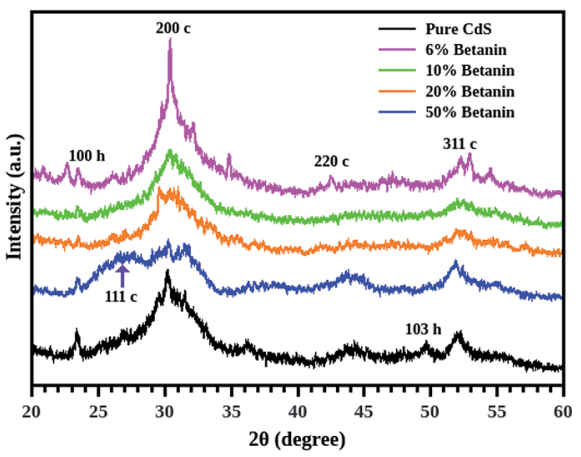

Fig. 2 X-ray diffraction patterns of pure CdS and CdS/betanin composites ( $6 \%$ - magenta, $10 \%$ - green, $20 \%$ - red, $50 \%$ - blue) shows mixed crystal structure. Broadening of the peak is observed in the composite system with increase in dye content. 
dynamics may be rather slow than the shell formation ${ }^{22}$ resulting in small sized core CdS particles. Further grain growth is prevented because of the organic shell of betanin. The composite with $6 \%$ dye content has impurity peaks between $30^{\circ}$ and $35^{\circ}$ due to the unreacted cadmium compounds. This may be resulted from the slow reaction rate induced by the betanin dye. For the sample containing $50 \%$ of betanin, the highest electron density is observed for the cubic plane of $(111 \mathrm{c})$ which indicates a change in orientation for the CdS nanocrystals. The choice of reactants, synthesis techniques and conditions can influence the formation of CdS, and the possibility of mixed phase formation is quite natural in chemical synthesis. X-ray diffraction data showed that most of the formed nanocrystals stabilizes in the cubic phase.

\section{Thermogravimetric analysis}

The dynamic TGA (mass variation with temperature at constant heat rate) measurements are conducted on 5 samples including fresh betanin, dried betanin, CdS and CdS/betanin composites (50\% and $75 \%$ ) (Fig. 3). As the fresh betanin has larger water content, sudden loss of mass is observed in the temperature change of $40-100{ }^{\circ} \mathrm{C}$. The degradation of the betanin dye is observed within the temp. of $204{ }^{\circ} \mathrm{C}$. The dried beetroot has also similar behaviour except the huge mass change at the beginning of the experiment. In the case of pure CdS powders, thermal stability (16\% loss of mass) is observed upto $644{ }^{\circ} \mathrm{C}$. The $50 \%$ betanin added CdS showed thermal stability upto $673{ }^{\circ} \mathrm{C}$ while the $75 \%$ betanin $\mathrm{CdS}$ core system showed stability upto $723{ }^{\circ} \mathrm{C}$. These results hint towards complete shelling of betanin on CdS nanoparticles (as no low temperature peaks corresponding to pure betanin is observed) the core/shell structure also ensured better stability with disintegration temperature.

\section{Transmission Electron Microscopy}

Morphological analysis of CdS/betanin composite ( $50 \%$ betanin) is carried out by employing TEM and the results are shown in Fig. 4. Here, all the particles are found to be spherical in shape. No irregularity in shape is observed. All particles are found to be below $17 \mathrm{~nm}$ (average particle size is $10 \mathrm{~nm}$ ) in

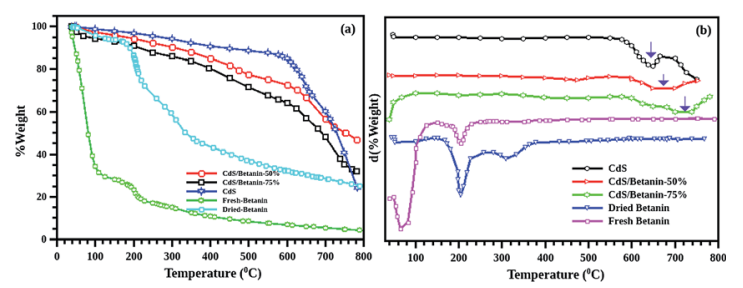

Fig. 3 (a) TG curve of CdS (blue), fresh (green) and dried betanin (cyan), CdS/betanin composites with dye content 50 (red) and 75\% (black) showing the percentage of weight loss during the heat treatment. Sudden loss of mass near $200^{\circ} \mathrm{C}$ shows the loss of water content in both betanin. From the derivative TG curve (b), it is clear that pure $\mathrm{CdS}$ has stability upto $644^{\circ} \mathrm{C}$ while the composite structure has higher thermal stability than CdS (upto $723^{\circ} \mathrm{C}$ for the sample with $75 \%$ of dye).

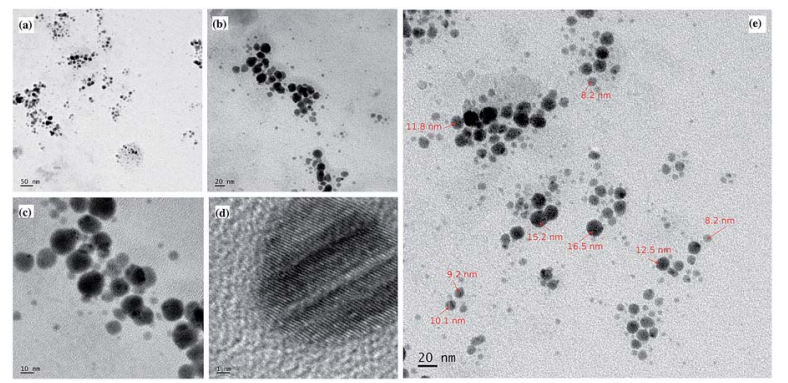

Fig. 4 High resolution transmission electron micrograph of CdS/ betanin composite $(50 \%)$ nanoparticles $(a-e)$. Most of the particles are spherical in shape and found in the size range of $8-17 \mathrm{~nm}$ with an average size of $10 \mathrm{~nm}$.

diameter. Particle which has a radius less than the exciton Bohr radius limit of $2.9 \mathrm{~nm}$ (ref. ${ }^{23}$ ) is considered as quantum mechanically confined particles. This confinement of particle leads to the formation of discrete energy levels. Here most of the particles are above $6 \mathrm{~nm}(8-17 \mathrm{~nm})$ in diameter and expected to behave like nanoparticles with weak to negligible quantum confinement effects. Similar behaviour is obtained for Ag/dye composite nanoparticles, a theoretical and experimental study of inorganic/organic core/shell nanoparticle ${ }^{24}$ by Lebedev et al. ${ }^{25}$ According to them, the silver/dye system behaves like a core/ shell nanoparticle by varying the size of the core. Since TEM images does not provide any evidence for the presence of dye, we can only assume that the CdS/betanin composite nanoparticle is behave like core/shell nanoparticles with CdS as core and betanin as the shell.

\section{X-ray photoelectron spectroscopy}

The surface composition of the CdS/betanin composite is analysed by employing XPS (X-ray Photoelectron Spectroscopy or ESCA, Electron Spectroscopy for Chemical Analysis), a very sensitive technique for the chemical analysis. The characterisation is carried out on surface and depth profiling was done upto $10 \mathrm{~nm}$. Here, the solid samples are irradiated with X-rays in vaccum and the emitted electron energy is analysing. Every component has distinctive set of binding energies and has unique spectrum.

The obtained XPS spectra depicted in the Fig. 5 demonstrate the peaks corresponding to the binding energy of the elements including $\mathrm{Cd}, \mathrm{S}, \mathrm{N}, \mathrm{C}$, and $\mathrm{O}$ in the composites with different

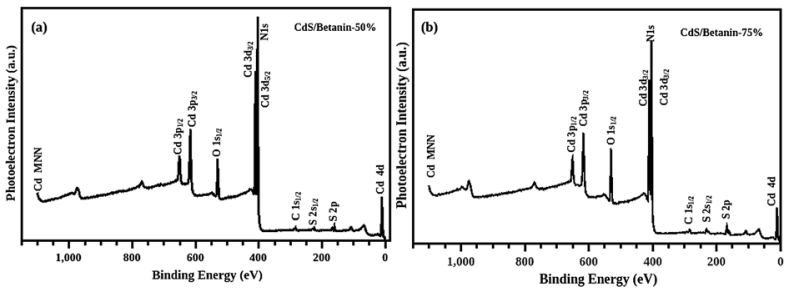

Fig. 5 XPS spectra of the sample CdS/betanin $-50 \%$ (a) and $75 \%$ (b) with a depth profiling of $10 \mathrm{~nm}$. The Cd3d peaks is overlapped with N1s at $\sim 400 \mathrm{eV}$. 
betanin content. The Cd-3d usually has a doublet ${ }^{26}$ and the best fit of the XPS data (Fig. 6(a) and (b)) was obtained with peaks at 404 and $410 \mathrm{eV}$ respectively indicate $3 \mathrm{~d}_{5 / 2}$ and $3 \mathrm{~d}_{3 / 2}$ due to spin orbit coupling of $3 \mathrm{~d}$ orbit. In the case of $\mathrm{S} 2 \mathrm{p}$, deconvolution of the non-Gaussian peak (Fig. 6(c) and (d)) predicts four fitted peaks, at $\sim 160,161,166$ and $167 \mathrm{eV}$. The peak at $\sim 161 \mathrm{eV}$ represents the $\mathrm{S}^{2-}$ atom while the peaks above $166 \mathrm{eV}$ assigned as the oxidized peak of sulfur groups found on the surface of the sample. ${ }^{27-30}$ The spectra exhibit well defined C1s and O1s peak which confirm the presence of betanin in the composite. The C1s has three peaks at 284, 286 and $288 \mathrm{eV}$ (Fig. 6(e) and (f)) respectively representing the $\mathrm{C}-\mathrm{C}, \mathrm{C}-\mathrm{O}$, and $\mathrm{C}=\mathrm{O}$ group. For the sample with $75 \%$ betanin content instead of $\mathrm{C}-\mathrm{O}$ bond at $286 \mathrm{eV},-\mathrm{O}-\mathrm{C}=\mathrm{O}-$ is observed at $292 \mathrm{eV} \cdot{ }^{31,32}$ The O1s has two peaks, at 529 and $532 \mathrm{eV}$ (Fig. $6(\mathrm{~g})$ and (h)), represents $\mathrm{C}=\mathrm{O}$ and $\mathrm{C}-\mathrm{O}$ bonds in the composite. We observed a peak at $402 \mathrm{eV}$, which is overlapped with the $\mathrm{Cd} 3 \mathrm{~d}$ peaks which indicate the presence of $=\mathrm{N}-$ in the composite..$^{33,34}$ The peaks at $402(=\mathrm{N}-)$
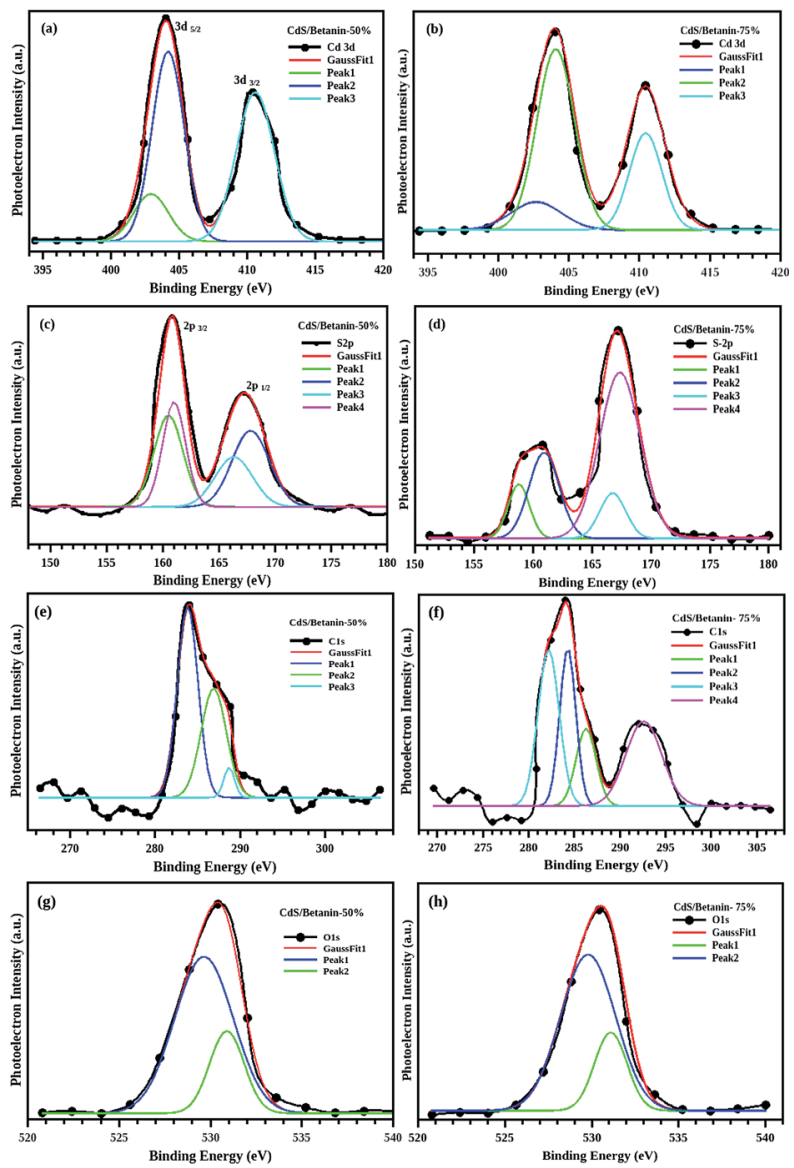

Fig. 6 The deconvoluted non Gaussian XPS peaks of Cd3d, S2p, C1s and $\mathrm{O} 1 \mathrm{~s}$. The doublet of $\mathrm{Cd} 3 \mathrm{~d}\left(3 \mathrm{~d}_{5 / 2}\right.$ and $\left.3 \mathrm{~d}_{3 / 2}\right)$ overlapped with $\mathrm{N} 1 \mathrm{~s}$ peak at $402 \mathrm{eV}$ for the sample with $50 \%$ (a) and $75 \%$ (b) betanin. The $\mathrm{S} 2 \mathrm{p}$ (c and d) has four deconvoluted peaks, in which peak at161 eV shows the $\mathrm{S}^{2-}$ in the composite and all the other peaks above $166 \mathrm{eV}$ shows the oxidized sulphur groups. $\mathrm{C}-\mathrm{C}, \mathrm{C}-\mathrm{O}$, and $\mathrm{C}=\mathrm{O}$ are the hidden peaks in $\mathrm{C} 1 \mathrm{~s}$ (e and $\mathrm{f}$ ). For $75 \%$ betanin, instead of peak at $286 \mathrm{eV}$, a peak at $292 \mathrm{eV}$ is observed indicates $-\mathrm{O}-\mathrm{C}=\mathrm{O}-$ group in the composite. The two peaks of $\mathrm{O} 1 \mathrm{~s}$ ( $\mathrm{g}$ and $\mathrm{h}$ ) clarify the presence of $\mathrm{C}=\mathrm{O}$ and $\mathrm{C}-\mathrm{O}$ groups.
529, 532, 284, 286, 288 and $292 \mathrm{eV}$ show the attachment of betanin in the CdS core. Furthermore, a ratio of $2: 1$ is recorded for $\mathrm{N}$ to $\mathrm{Cd}$ confirming the attachment of 1 each betanin molecule on a CdS molecule (one betanin molecule possess $-\mathrm{NH}-$ and $=\mathrm{N}$ - groups).

\section{Optical studies}

FT-IR spectroscopy. FT-IR spectra of the CdS and CdS/ betanin (50\%) are recorded in the wavelength range of 4000 to $500 \mathrm{~cm}^{-1}$ which are shown in the Fig. 7. The spectrum has two areas $^{35}$ of interest, where the region from 4000 to $1500 \mathrm{~cm}^{-1}$ represents the characteristic peak of functional groups known as "important" or "functional group region". The remaining part ( 1500 to $400 \mathrm{~cm}^{-1}$ ) is referred as the "finger print region" of the FT-IR spectrum. Here, the FTIR spectra show a broad peak at $3345 \mathrm{~cm}^{-1}$ and $2158 \mathrm{~cm}^{-1}$ represent the stretching vibration of $-\mathrm{OH}$ bond which indicates the strong interaction of CdS with water molecules. The hydroxyl peak in CdS/betanin sample exhibits shift in band position. The presence of hydroxyl group is quite common in the case of CdS grown in solution process, ${ }^{36}$ and the interaction with surroundings takes place via hydrogen bonding by the surface bounded $\mathrm{H}_{2} \mathrm{O}$ molecules. ${ }^{37}$ The peak at $1634 \mathrm{~cm}^{-1}$ might have originated due to the bending of $-\mathrm{OH}$ bond of water molecule. ${ }^{38}$ Since sulfur is treated as a potential $\mathrm{H}$-bond acceptor, ${ }^{39}$ the $-\mathrm{OH}$ bond of water is attached to the sulfur atom of CdS. This $\mathrm{S}$... OH bond is replaced by the $\mathrm{COOH}$ group of the betanin. The bond length of $\mathrm{S}$...COOH group is comparatively larger and has less energy than S...OH. As a result of this, $-\mathrm{OH}$ bonded peaks such as 3345, 2158, $1645 \mathrm{~cm}^{-1}$ are shifted towards low energy region (3261, 2139, 1571 respectively) of the FT-IR spectra. This shift in peak confirm the formation CdS/betanin complex structure. Peaks at 1445 and $1093 \mathrm{~cm}^{-1}$ represent the trace vibrations of $\mathrm{NH}^{4-}$ and $\mathrm{SO}^{4-}$ respectively. ${ }^{40}$ The material peaks found in the lower wavelength region, (the peaks 586, 651 and $795 \mathrm{~cm}^{-1}$ ) represent the stretching mode of $\mathrm{Cd}-\mathrm{S}$ bond. The peaks in the finger print region are also shifted downwards on betanin addition, which may be arose due to the CdS/betanin core/shell formation with thicker shell.

UV-Vis spectrophotometry. The absorbance of all the samples is recorded in the wavelength range of 400 to $800 \mathrm{~nm}$. The observed results are shown in Fig. 8(a). Effect of betanin on the absorption properties of CdS is clear from the graph. Since

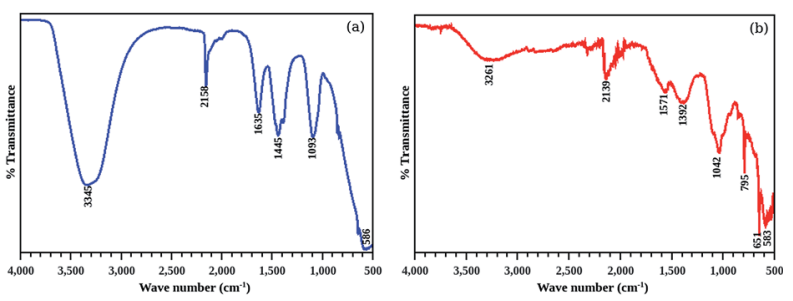

Fig. 7 FT-IR spectra of pure CdS (a) and CdS/betanin (b, 50\%) nanoparticles. The peaks at $3345,2158,1645 \mathrm{~cm}^{-1}$ shows the $\mathrm{S}-\mathrm{OH}$ bond in the $\mathrm{CdS}$ nanoparticles and it is shifted to lower energy region to form $\mathrm{S}-\mathrm{COOH}$ bond in the composite system. 

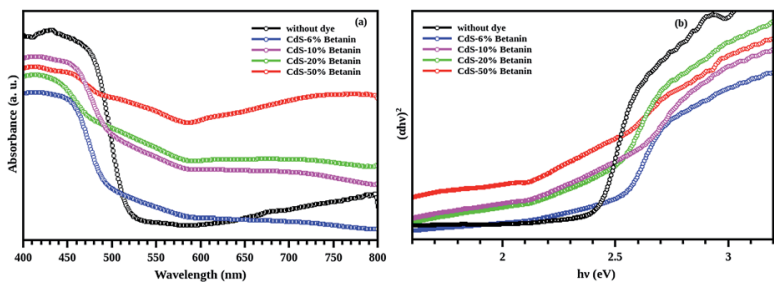

Fig. 8 (a) Absorption spectra of CdS with and without betanin dye and (b) the corresponding Tauc plot. The $6 \%$ betanin (blue) added sample is blue shifted with respect to the CdS pure, due to the presence of small particles. All the composite has additional peak in the lower wavelength region. The samples 6\%, 10\% (magenta), 20\% (green) and 50\% (red) respectively has CdS band edge at 2.46, 2.43, 2.38, $2.16 \mathrm{eV}$ respectively. This shift in energy of the composite hint towards the increased core size with betanin content. The intensity of the peaks increased with the betanin content.

CdS is a direct band gap material, nature of transition is direct allowed (ie, $n=2$ ), and hence, the $Y$-axis of Tauc plot is $(\alpha h \nu)^{2}$. From the Tauc plot (Fig. 8(b)), the band gap of all the samples are estimated by extrapolating the linear portion to the zero of $X$-axis and the values are tabulated (Table 1).

It is observed that the band gaps of CdS/betanin composites are found to be decreased from $2.46 \mathrm{eV}$ to $2.16 \mathrm{eV}$. The color variation of the sample with dye percentage and the energy band diagram is shown in Fig. 9. The valence $\left(E_{\mathrm{v}}\right)$ and conduction $\left(E_{\mathrm{c}}\right)$ band edge calculations are done using the relation $E_{\mathrm{v}}=-\chi-0.5 E_{\mathrm{g}}$ and $E_{\mathrm{c}}=-\chi+0.5 E_{\mathrm{g}}$ where $-\chi$ is the absolute electronegativity (for $\operatorname{CdS} \chi=5.18\left({ }^{(\text {ref. }}{ }^{41}\right)$ ). From the band energy diagram, it is clear that the conduction band of betanin ${ }^{42}$ lies in between the conduction and valence band of CdS. The incorporation of dye in CdS has resulted in the formation interband sub levels (Fig. 10(a)) in between VB and $\mathrm{CB}$, thereby reducing the band gap and increasing the tunability of the band edge. Our results support the findings by Okoli et al., ${ }^{43}$ where the band gap of crystalline $\mathrm{TiO}_{2}(3 \mathrm{eV})$ was reduced to $2.59 \mathrm{eV}$ on dye sensitization. They used anthocyanin, a natural dye extracted from Hibiscus sabdariffa for the sensitization of semiconductor. The shift in absorption observed for the dye sensitized sample may be originated from the complexation of dye molecule with the metal ions. ${ }^{44}$ In most of the cases, impurity addition in CdS reduces the band gap with increase in concentration. ${ }^{45-47}$

The absorption spectra of composite system have an additional band edge (bare CdS has only one absorption edge at $511 \mathrm{~nm}$ corresponding to the energy $2.42 \mathrm{eV}$ ) in the lower wavelength region. The energy corresponding to the intermediate band (since its value lies below the band gap of the synthesized CdS nanoparticle) is shifted towards the red region with betanin percentage. The intermediate band observed in the energy range of $\sim 1.75 \mathrm{eV}$, can help CdS to absorb of lower and higher energy photons simultaneously from the solar radiation, leading to the increased efficiency of CdS based solar cell. Obviously, the intermediate band is resulted from the betanin dye and the behaviour of the absorption spectra hinting towards the formation of core/shell like structure in the composite system with CdS as core and betanin dye as outer shell.
Table 1 Band gap of sample measured from the Tauc plot

\begin{tabular}{llll}
\hline Sample & $\begin{array}{l}\text { Amount of } \\
\text { betanin dye }\end{array}$ & $\begin{array}{l}\text { Band gap of } \\
\text { CdS }(\mathrm{eV})\end{array}$ & $\begin{array}{l}\text { Intermediate } \\
\text { band }\end{array}$ \\
\hline CdS without dye & $0 \%$ & 2.42 & - \\
CdS with betanin & $6 \%$ & 2.46 & 1.90 \\
dye & $10 \%$ & 2.43 & 1.89 \\
& $20 \%$ & 2.38 & 1.88 \\
& $50 \%$ & 2.16 & 1.62 \\
\hline
\end{tabular}

According to Lubedev et al., both theoretical and experimental absorption studies of metal/dye core/shell system has two peaks, one from the metal due the localized surface plasmon resonance and second one due to the electronic excitation of the dye. The peak corresponds to the metal shift towards the higher wavelength region with an increase in shell thickness. Similarly, the absorption edge corresponds to dye also shift towards the red region with shell thickness. Here, the absorption peak of betanin is obtained at $\sim 530 \mathrm{~nm}$ (Fig. 7(b)) and get shifted to a wavelength of $\sim 650 \mathrm{~nm}$ and is higher for the composite system. In account of the theoretical approach of Lubedev et al., we can predict the behaviour of our CdS/betanin core/shell composite system. The intensity of first (CdS) and the second (betanin) absorption edge increases with betanin content which implies that the core CdS nanoparticle has fixed size and the shell thickness is varying with dye percentage. In addition to the shift in absorption edge, the intensity also increased with betanin content. The concentration of the betanin solution is a factor that affects the absorption edge. For less concentrated solution, no additional peak corresponds to betanin was observed (ESI Fig. S1(a) †). As the dye percentage increases from $50 \%$ to larger amount, redshift in absorption edge is observed. The band energy corresponds to CdS will decrease further. This will reduce the higher energy photon absorption, and affects the output result. In general, the optical characterisation of the composite nanoparticles clearly demonstrates the importance of geometrical parameters of composite structures in tailoring the optical properties.

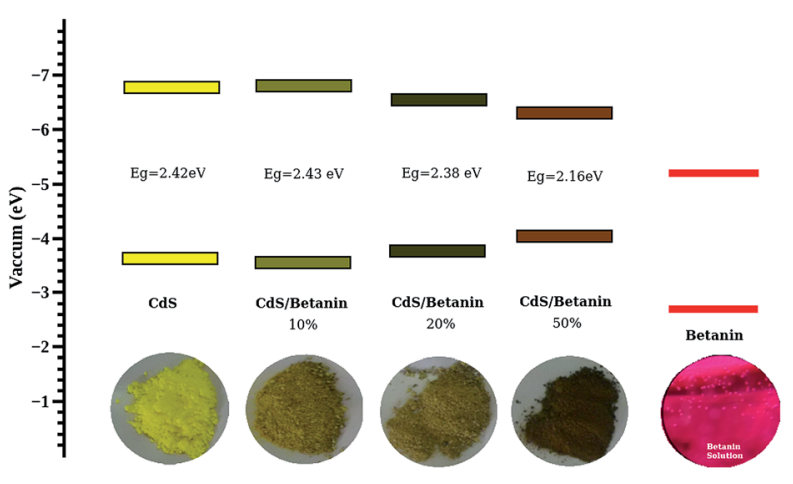

Fig. 9 The energy band diagram of $\mathrm{CdS}$ and $\mathrm{CdS} /$ betanin composite nanoparticles calculated using absolute electronegativity of CdS and the observed band edge of the CdS as well as composites. 


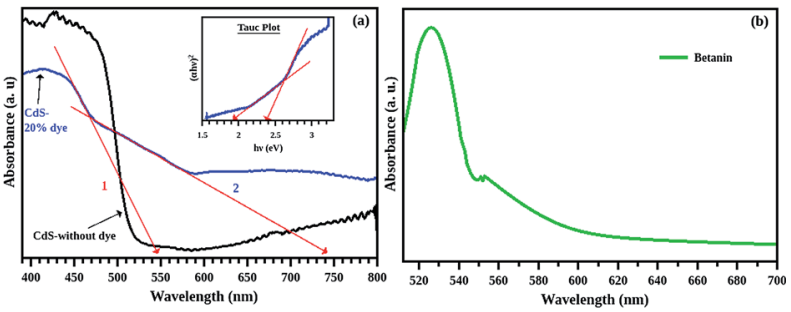

Fig. 10 (a) Absorption spectra and Tauc plot (inset) of pure CdS (black) and CdS/betanin composite (blue) with $20 \%$ betanin dye (arrow (1)band edge of CdS, arrow (2)-intermediate band), (b) absorption spectrum of betanin solution which has maximum absorption at $530 \mathrm{~nm}$.

\section{Dielectric studies}

The dielectric studies of the CdS as well as CdS/betanin composite (50\% betanin) are shown in Fig. 11. Capacitance $(C)$, tangent of the dielectric loss or the dissipation factor $(\tan \delta)$ and conductance $(G)$ of the pelletized sample is measured at room temperature. Illumination with $300 \mathrm{~W}$ incandescent bulb is done to study the effect of light on the conductivity of the samples at different intensities by changing the distance between the light source and the sample holder $(25,50,75 \mathrm{~cm})$ as well as the time of illumination. The dielectric constant $\left(\varepsilon_{\mathrm{r}}\right)$ of the samples is calculated from the equation

$$
\varepsilon_{\mathrm{r}}=C d / \varepsilon_{0} A
$$

where $d$ is the thickness and $A$ is the area of the sample. From the measured conductance, conductivity $(\sigma)$ is calculated using the following general formula.

$$
\sigma=G d / A
$$
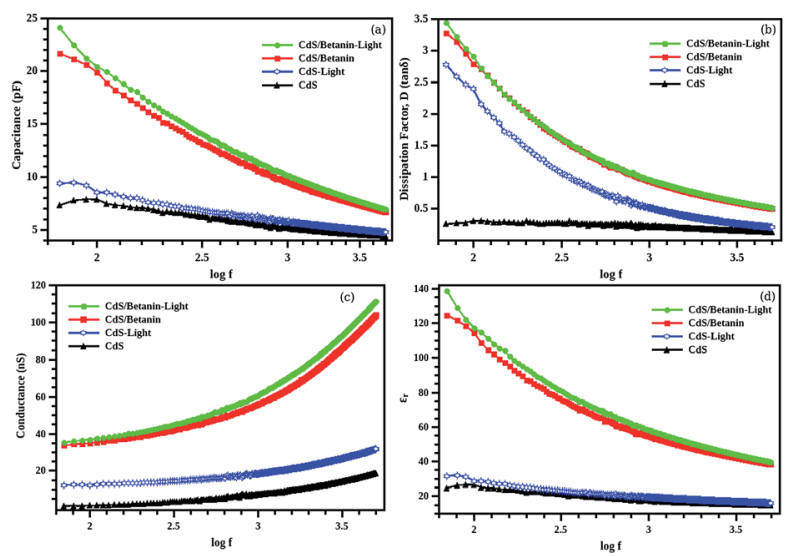

Fig. 11 (a) Capacitance (b) dissipation factor (c) conductance and (d) dielectric constant of CdS and CdS/betanin (50\%) samples with and without light illumination. Enhanced capacitance, D-factor, conductance and dielectric constant is observed for light illuminated samples. Among CdS (black), illuminated CdS (blue), CdS/betanin composite (red), the illuminated composite (green) system has higher conductance of the order of nano Siemens (nS).
All the quantities are plotted as a function of frequency (50 $\mathrm{Hz}$ to $5000 \mathrm{~Hz}$ ). The properties such as capacitance, dissipation factor and conductance are extremely larger for CdS/ betanin core/shell structure. Clearly the modification is resulted from the betanin dye. Almost all the semiconductors show slight increase in conductivity upon light illumination, due to the increase in carrier charge density. Here, the CdS's conductivity (Fig. 12) is increased upon light illumination, since the energy for knocking out the electron from the valence band to the conduction band is made available in the optical form. Concurrently, a huge enhancement in conductivity is observed in CdS/betanin composites on illumination due to the transfer of photogenerated electrons from the conduction band of betanin to the conduction band of CdS. ${ }^{48}$ This will create large number of free carriers in the conduction band of CdS in the composite system resulting in an increased electrical conductivity. Our findings agree with Nabanita Pal et al. ${ }^{49}$ They reported an enhanced photoconductivity in mesoporous titania doped with rose bengal dye than the undoped one.

Time of illumination also affects the conductance of the composite structure (Fig. 13(a)). We illuminated the samples for 1, 4, 8 and 20 minutes keeping the sample-light source distance as fixed $(25 \mathrm{~cm})$. The maximum conductance is observed for an illumination of 8 minutes. This hike in conductivity is due to the interband transition assisted by the betanin dye. The conductance of the sample is found to be dropped at an illumination of 20 minutes to the conductance value of CdS without illumination. This may be due to the degradation of dye ${ }^{20}$ resulted from the higher intensity light illumination. Sample and light source distance is varied from 25 to $75 \mathrm{~cm}$ with a step size of $25 \mathrm{~cm}$ (illumination time is fixed less than $1 \mathrm{~min}$ ). The conductance is found to be increased in the lower frequency (up to $2 \mathrm{kHz}$ ) region as the light intensity is increased $(25 \mathrm{~cm}$ distance has the max light illumination intensity) and is found to be decreased in the higher frequency region (Fig. 13(b)). Higher conductance value is obtained at a distance of $75 \mathrm{~cm}$ (min intensity) for higher frequency $(10 \mathrm{kHz})$. After measuring the effect of highest intensity light on the composite sample, the light source is switched off and measured the conductance. Maximum conductance is observed in the low frequency $(1 \mathrm{kHz})$ region and is decreased as the frequency reached to $10 \mathrm{kHz}$. This decrease may be resulting from the decay process that usually observed in dyes. ${ }^{\mathbf{5 0 , 5 1}}$ This phenomenon is known as bleaching effect ${ }^{52}$ in dye molecules due
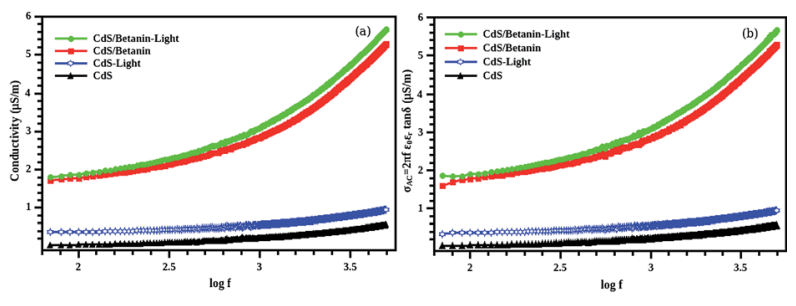

Fig. 12 Calculated conductivity of $\mathrm{CdS}$ and CdS/betanin composite $(50 \%)$ structure with two different methods ((a) using conductance (b) using dielectric constant and dissipation factor). Both case enhanced conductance is observed for the light illuminated composite (green) system. 

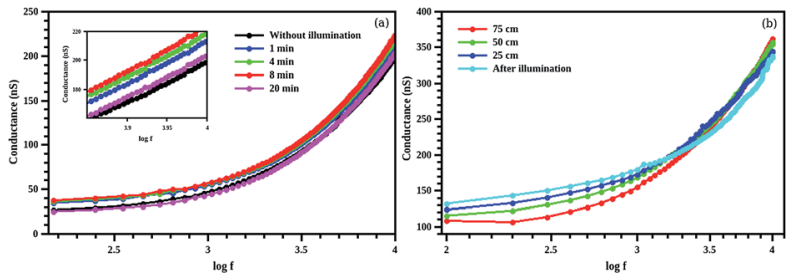

Fig. 13 The photo conductance of $\mathrm{CdS} /$ betanin composite $(50 \%)$ at different illumination time (a) and different intensity (b) of light. The inset shows the zoomed view of the conductance. Up to 8 minute the conductance of the sample increased with light illumination, while for $20 \mathrm{~min}$, due to the degradation of the betanin dye, drop in conductance is observed. The intensity of the white light also affects the conductance of the composite by increasing the conductance in the lower frequency region $(1 \mathrm{kHz})$, decreasing in the higher frequency region $(10 \mathrm{kHz})$.

the exposure of highly intense light. As a result of this, the dye molecule may detach from the CdS core and introduce electrons trap centers..$^{53}$ These trap centres at the surface will be attracted by the atmospheric oxygen and cause electron scavenging which will result in a decrease of conductance via decreasing the free carrier charge formation in the core/shell system.

\section{Conclusions}

In summary, we have successfully synthesized organic inorganic hybrid core/shell nanostructures by wet chemical route. CdS was the chosen inorganic core, while betanin, an organic dye, was deposited as the shell. The morphological analyses show that the average core diameter of the system was $\sim 10 \mathrm{~nm}$. It was observed that the deposition of an organic shell of betanin over the CdS core resulted in the modification of the band edge and the band gap was found to be red shifted by $0.26 \mathrm{eV}$ from the pure CdS nanoparticles. The thermal analyses showed that the pure betanin has a disintegration temperature $\sim 200{ }^{\circ} \mathrm{C}$ while the core/shell structures showed high thermal stability, even better than the parent CdS nanoparticles, ruling out the chance of precipitation of betanin separately. To confirm the same, FTIR and XPS analyses were performed. The FTIR spectra showed shift in peaks corresponding to $\mathrm{S}-\mathrm{OH}$ bond of the CdS nanoparticles to lower energy region to form S$\mathrm{COOH}$ bond in the composite system, while the XPS analysis conducted up to a depth profile of $10 \mathrm{~nm}$ showed the attachment of betanin to the CdS with an overall $\mathrm{Cd}: \mathrm{N}$ ratio as $\sim 1: 2$. The conductivity and photoconductivity of the CdS/betanin core/shell structures were found much superior to the parent CdS nanoparticles. Hence, from this current investigation, we demonstrate the possibility to employ the inorganic-organic hybrid quantum dots and other nanostructures for enhanced photoconductivity which can offer more efficient thin film energy harvesters.

\section{Conflicts of interest}

There are no conflicts to declare.

\section{Acknowledgements}

N. Susha gratefully acknowledges the financial support from DST for the INSPIRE fellowship. Author S. S. N. thanks, UGC (F. No. 201/2013), DST (YSS/2014/000431), DBT (6292-P52/RGCB/ $\mathrm{PMD} / \mathrm{DBT} / \mathrm{RPKT} / 2015)$ and Central University of Kerala for financial support.

\section{Notes and references}

1 B. R. Sankapal, E. Goncalves, A. Ennaoui and M. C. LuxSteiner, Thin Solid Films, 2004, 451-452, 128-132.

2 J. Millan, P. Godignon, X. Perpina, A. Perez-Tomas and J. Rebollo, IEEE Trans. Power Electron., 2014, 29, 2155-2163.

3 A. Zapico, I. Gabiola, S. Apinaniz, F. Santiago, A. Pujana, A. Rodriguez and F. Briz, in 15th International Power Electronics and Motion Control Conference and Exposition, EPE-PEMC 2012 ECCE Europe, IEEE, 2012, pp. DS1a.7-1DS1a.7-6.

4 A. Elasser and T. P. Chow, Proc. IEEE, 2002, 90, 969-986.

5 J. Puthussery, A. Lan, T. H. Kosel and M. Kuno, ACS Nano, 2008, 2, 357-367.

6 J. B. Sambur, T. Novet and B. a. Parkinson, Science, 2010, 330, 63-66.

7 M. B. Ortuño-López, M. Sotelo-Lerma, A. Mendoza-Galván and R. Ramírez-Bon, Vacuum, 2004, 76, 181-184.

8 L. Shi, Y. Qin, J. Hu, Y. Duan, L. Qu, L. Wu and G. Tang, EPL, 2014, 106, 57001.

9 D. Lei, Y. T. Shen, Y. Y. Feng and W. Feng, Sci. China: Technol. Sci., 2012, 55, 903-912.

10 H. J. Watzke and J. H. Fendler, J. Phys. Chem., 1987, 91, 854861.

11 A. K. Mishra, N. Garg, K. K. Pandey and V. Singh, J. Phys.: Conf. Ser., 2012, 377, 12012.

12 B. A. Simmons, S. Li, V. T. John, G. L. McPherson, A. Bose, W. Zhou and J. He, Nano Lett., 2002, 2, 263-268.

13 S. K. Mehta, S. Kumar, S. Chaudhary and K. K. Bhasin, Nanoscale, 2010, 2, 145-152.

14 M. Grätzel, J. Photochem. Photobiol., C, 2003, 4, 145-153.

15 R. Salehi, M. Arami, N. M. Mahmoodi, H. Bahrami and S. Khorramfar, Colloids Surf., B, 2010, 80, 86-93.

16 H. Miyake and H. Kozuka, J. Phys. Chem. B, 2005, 109, 1795117956.

17 S. Suhaimi, M. M. Shahimin, Z. A. Alahmed, J. Chyský and A. H. Reshak, Int. J. Electrochem. Sci., 2015, 10, 2859-2871.

18 A. Sturzoiu, M. Stroescu, A. Stoica and T. Dobre, UPB Sci. Bull. B: Chem. Mater. Sci., 2011, 73, 145-156.

19 T. Esatbeyoglu, A. E. Wagner, R. Motafakkerazad, Y. Nakajima, S. Matsugo and G. Rimbach, Food Chem. Toxicol., 2014, 73, 119-126.

20 A. Thankappan, V. P. N. Nampoori and S. Thomas, Opt. Laser Technol., 2016, 83, 28-34.

21 A. Abdolahzadeh Ziabari and F. E. Ghodsi, Sol. Energy Mater. Sol. Cells, 2012, 105, 249-262.

22 A. C. A. Silva, S. W. Da Silva, P. C. Morais and N. O. Dantas, ACS Nano, 2014, 8, 1913-1922.

23 W. Chen, K. Chen, Q. Peng and Y. Li, Small, 2009, 5, 681-684. 
24 R. Ghosh Chaudhuri and S. Paria, Chem. Rev., 2012, 112, 2373-2433.

25 V. S. Lebedev, A. G. Vitukhnovsky, A. Yoshida, N. Kometani and Y. Yonezawa, Colloids Surf., A, 2008, 326, 204-209.

26 A. Veamatahau, B. Jiang, T. Seifert, S. Makuta, K. Latham, M. Kanehara, T. Teranishi and Y. Tachibana, Phys. Chem. Chem. Phys., 2015, 17, 2850-2858.

27 S. Wei, S. Xu, A. Agrawral, S. Choudhury, Y. Lu, Z. Tu, L. Ma and L. A. Archer, Nat. Commun., 2016, 7, 11722.

28 C. Wang, Z. Guo, W. Shen, A. Zhang, Q. Xu, H. Liu and Y. Wang, J. Mater. Chem. A, 2015, 3, 6064-6072.

29 H. Huang, Y.-C. Lu, A.-J. Wang, J.-H. Liu, J.-R. Chen and J.-J. Feng, RSC Adv., 2014, 4, 11872-11875.

30 N. Kakuta, J. M. White, A. Campion, A. J. Bard, M. A. Fox and S. E. Webber, J. Phys. Chem., 1985, 89, 48-52.

31 J.-M. Lee, J.-W. Kim, J.-S. Lim, T.-J. Kim, S.-D. Kim, S.-J. Park and Y.-S. Lee, Carbon Lett., 2007, 8, 120-126.

32 Y. Wu, L. Xiong, X. Qin, Z. Wang, B. Ding, H. Ren and X. Pi, IOP Conf. Ser.: Mater. Sci. Eng., 2015, 87, 12082.

33 K. Diller, F. Klappenberger, F. Allegretti, A. C. Papageorgiou, S. Fischer, D. A. Duncan, R. J. Maurer, J. A. Lloyd, S. C. Oh, K. Reuter and J. V. Barth, J. Chem. Phys., 2014, 141, 144703.

34 A. Beheshti, F. Hashemi, F. Behvandi, P. Mayer and D. Atzei, Inorg. Chem. Front., 2018, 5, 694-704.

35 R. Helm, Invitation to Organic Chemistry, ed. Johnson A. William, 2000, vol. 77.

36 S. S. Liji Sobhana, M. Vimala Devi, T. P. Sastry and A. B. Mandal, J. Nanopart. Res., 2011, 13, 1747-1757.

37 V. Ladizhansky, G. Hodes and S. Vega, J. Phys. Chem. B, 1998, 102, 8505-8509.

38 G. Sivakumar, V. Hariharan and K. Abith, Elixir Opt. Mater., 2012, 48, 9433-9436.
39 S. Scheiner, Noncovalent Forces, Springer International Publishing, Cham, 2015.

40 A. Sabah, S. Siddiqi and S. Ali, World Acad. Sci. Eng. Technol., 2010, 4, 82-89.

41 X. Yong and M. A. A. Schoonen, Am. Mineral., 2000, 85, 543556.

42 C. I. Oprea, A. Dumbrava, I. Enache, A. Georgescu and M. A. Gîrţu, J. Photochem. Photobiol., A, 2012, 240, 5-13.

43 L. U. Okoli, J. O. Ozuomba and A. J. Ekpunobi, Res. J. Phys. Sci., 2013, 1, 6-10.

44 N. Li, N. Pan, D. Li and S. Lin, Int. J. Photoenergy, 2013, 2013, 1-5.

45 M. Thambidurai, N. Muthukumarasamy, S. Agilan, N. Sabari Arul, N. Murugan and R. Balasundaraprabhu, J. Mater. Sci., 2011, 46, 3200-3206.

46 A. Firdous, D. Singh and M. M. Ahmad, Appl. Nanosci., 2013, 3, 13-18.

47 M. Thambidurai, N. Muthukumarasamy, D. Velauthapillai and C. Lee, J. Mater. Sci.: Mater. Electron., 2013, 24, 45354541.

48 P. Maity, T. Debnath and H. N. Ghosh, J. Phys. Chem. Lett., 2013, 4, 4020-4025.

49 N. Pal, M. Paul, A. Bera, D. Basak and A. Bhaumik Asim, Anal. Chim. Acta, 2010, 674, 96-101.

50 D. Patterson and B. Pilling, Trans. Faraday Soc., 1966, 62, 1976.

51 S. K. Dey and N. B. Manik, Appl. Biochem. Biotechnol., 2001, 96, 55-62.

52 S. Zongo, MPhil thesis, University of the Western Cape, 2012.

53 Z. Li, C. Rochford, F. J. Baca, J. Liu, J. Li and J. Wu, Nanoscale Res. Lett., 2010, 5, 1480-1486. 